\title{
Fatores Associados à Depressão em Líderes Religiosos de uma Denominação Pentecostal
}

\author{
Rafael Zaneripe de Souza Nunes ${ }^{1}$; Rosimeri Vieira da Cruz de Souza ${ }^{2}$; Amanda Castro ${ }^{3}$
}

\begin{abstract}
Resumo: Um dos temas emergentes atualmente na área da psicologia é a relação entre espiritualidade, saúde mental e qualidade de vida. O presente estudo teve como objetivo contribuir para a compreensão do papel da espiritualidade na saúde mental dos líderes religiosos, e seus efeitos em fatores associados à depressão. Dessa forma, aplicou-se o Inventário Beck de Depressão e um questionário com perguntas relacionadas a questões psiquiátricas nos líderes religiosos de uma Igreja Pentecostal em uma cidade do extremo sul de Santa Catarina. O estudo revelou que, embora apenas $10 \%$ da amostra tenham apresentado grau leve de depressão, outros fatores devem ser analisados em pesquisas posteriores. A amostra identificou outros transtornos psiquiátricos que devem ser investigados nas lideranças religiosas evangélicas.
\end{abstract}

Palavras-chave: Espiritualidade, depressão, religião, psicologia, pastores.

\section{Depression-Related Factors in Religious Leaders of a Pentecostal Church}

\begin{abstract}
One of the emerging themes currently in the field of psychology is the relationship between spirituality, mental health, and quality of life. The present study aimed to contribute to the understanding of the role of spirituality in the mental health of religious leaders, and its effects on factors associated with depression. Thus, the Beck Depression Inventory and a questionnaire with questions related to psychiatric issues were applied to the religious leaders of a Pentecostal Church in a city in the extreme south of Santa Catarina. The study found that although only $10 \%$ of the sample had a mild degree of depression, other factors should be analyzed in subsequent research. The sample identified other psychiatric disorders that should be investigated in evangelical religious leaderships.
\end{abstract}

Keywords: Spirituality, depression, religion, psychology, clergy.

\footnotetext{
${ }^{1}$ Graduado em Psicologia, Universidade do Extremo Sul Catarinense - Criciúma. Rua João Paes n 409, Bairro Santa Augusta, Criciúma, SC. rafaelzaneripe.psico@gmail.com, (48) 984050833.

${ }^{2}$ Professora do Curso de Graduação em Psicologia. Universidade do Extremo Sul Catarinense - Criciúma. Especialista Terapia Cognitiva Comportamental e Mestre em Administração. Rua José Studzinski, n 410, Bairro Jaqueline, Içara, SC. rosimerivieira@unesc.net, (48) 991259968.

${ }^{3}$ Professora do Curso de Graduação em Psicologia. Universidade do Extremo Sul Catarinense- Criciúma. Mestre em Psicologia e Especialista em Psicologia do desenvolvimento. Rua Rio dos Cedros $\mathrm{n}^{\circ}$ 188, Bairro Santa Augusta, Criciúma, SC. amandacastrops@gmail.com, (48) 988091109.
} 


\section{Introdução}

A espiritualidade dentro do contexto da saúde mental está tomando cada vez mais espaço. Temas envolvendo a relação entre espiritualidade e psique se tornam imprescindíveis para os profissionais da saúde que pretendem ter uma visão apurada acerca de todas as esferas que compõe o ser humano. Conforme Murakami e Campos (2012) a religião propicia uma leitura do sofrimento mental que lhe propicia ou certeza de propósito, oportunizando uma resignificação do sofrimento mental através de parâmetros religiosos.

Sendo a espiritualidade algo extremamente presente na vida de pastores e lideres religiosos no geral, o presente estudo tem como objetivo contribuir para pesquisas nesse campo, investigando a relação entre depressão e a liderança religiosa. Tem-se como base a problemática encontrada por Deus (2008), onde foi investigado "A influência do sentimento religioso sobre cristãos portadores de depressão”. Segundo o autor, na amostra de sua pesquisa uma porcentagem significativa de religiosos (pastores) apresentou particularidades relacionadas à depressão que necessitam de mais estudos para melhor compreensão dos dados encontrados. A hipótese a ser considerada nesse estudo é que o estresse causado pelo exercício da profissão pastoral ou de líder de uma comunidade cristã pode ser um fator desencadeante para a depressão.

Para realizar uma análise da problemática acima, entrou-se em contato com uma igreja protestante que tinha um número considerável de congregações em um município do sul catarinense, onde foi realizada a coleta de dados. Segundo Ebert e Soboll (2009), por mais que a função pastoral consista na atividade de aconselhamento e seja compreendida como fonte de prazer na profissão, há também uma vivência de sofrimento. Pois a mesma atividade que é fonte de prazer também é apontada como fonte de desprazer, o que gera cansaço e desgaste, o que corrobora com a importância do tema.

O autor Deus (2009), ressalta a importância de uma investigação mais aprofundada das relações da profissão pastoral com os transtornos depressivos. Afirmando que o tema era ainda pouco explorado e que necessitava de mais pesquisa e estudo, essa pesquisa foi feita partindo da reflexão dessa problemática com o objetivo de investigar a prevalência e os fatores associados à depressão nos pastores ou lideres cristãos, ou seja, pessoas que estão ligadas diretamente a esfera espiritual. Pode-se constatar a falta de conteúdo sobre o tema ao digitar os descritores depressão e espiritualidade no indexador BVS-Psi, 11 artigos são encontrados na 
base de dados Scielo. Destes artigos 2 eram de revisão teórica sobre saúde mental e espiritualidade, 1 consistia na validação de uma escala e o restante fazia análise da espiritualidade em pacientes hospitalizados com adoecimentos distintos. Portanto, nenhum dos artigos fez menção à profissão pastoral, o que denota a relevância científica desta temática no âmbito da Psicologia.

\section{Depressão}

A depressão é uma psicopatologia muito conhecida nos dias atuais, e embora muito se fale sobre ela, ainda existem diversas ideias pré-concebidas e errôneas sobre esse transtorno. Para se diagnosticar "depressão" devem-se levar em conta diversos critérios diagnósticos e ter em mente a complexidade subjetiva que está presente no individuo acometido pelo transtorno. Pode-se perceber a complexidade do tema por meio do Manual de Diagnóstico e Estatística dos Transtornos Mentais 5. a edição (APA, 2014), onde os transtornos depressivos incluem uma lista de diversas psicopatologias: o distúrbio da desregulação do humor, transtorno depressivo maior, transtorno depressivo persistente e etc.

De acordo com Tavares (2010), a depressão e suas variadas formas e classificações ganharam destaque na sociedade, e devido ao aumento de diagnósticos dessa psicopatologia tornou-se cada vez mais comum ouvir alguém dizer que sofre desse "mal do século".

Por meio disso, o termo depressão se torna emergencial, pois segundo Tavares (2010), a doença acabou se tornando uma das principais causas de afastamento do trabalho e limitando os indivíduos nas suas dimensões sociais, afetivas e coletivas.

Os sintomas mais comuns de depressão são: humor deprimido; irritabilidade; ansiedade e angústia; desânimo e cansaço; maior esforço para realizar atividades que anteriormente realizava com menos esforço; apatia e desinteresse; medo e insegurança; vazio e desesperança; dificuldade em sentir prazer em atividades anteriormente prazerosas; autoestima rebaixada; ideias desproporcionais de culpa; alterações de sono; alterações de peso; diminuição da vontade sexual; dificuldade em concentração e atenção; esquecimentos frequentes; vontade de "deixar de viver"; ideias de suicídio; dores pelo corpo e outros sintomas clínicos (gastrointestinais, cardiovasculares, dermatológicos, tonturas) (Deus, 2009, p.195).

Segundo Sezini e Gil (2014, p.40), “A depressão é uma doença de etiologia multifatorial que atinge aproximadamente 10 milhões de brasileiros e 340 milhões de pessoas em todo o 
mundo.". Se fizermos um paralelo com as informações da Organização Mundial da Saúde (2009, citado em Tavares 2010, p.67) a depressão no ano de 2009 já era um transtorno mental comum que afetava 121 milhões de pessoas em todo mundo. Atualmente a Organização Mundial da Saúde (2018) diz que o número de pessoas acometidas pelo transtorno é de mais de 300 milhões, o que vai de encontro com as informações de Sezini e Gil (2014), e demonstra o crescimento do número de casos na população mundial. Diante disso podemos ver que o problema da depressão na atualidade chama atenção pela problemática e proporção que assume.

A Secretária de Estado da Saúde de Santa Catarina (SES-SC, 2016 p.249) afirma que:

Do ponto de vista clinico, deve-se diferenciar depressão enquanto sintoma, enquanto síndrome, enquanto transtorno e enquanto doença. A presença de um ou mais sintomas não implica, necessariamente, que haja uma doença. Muitas vezes, em situações adversas envolvendo perdas ou autocritica, sentimentos depressivos são sinais de saúde mental e favorecem o amadurecimento do sujeito.

Segundo Monteiro e Lage (2007), o conceito de depressão tem vários sinônimos, e cada um dos conceitos demonstra uma linguagem que retrata aspectos de abordagens positivistas que influenciaram a psicopatologia em busca de um rigor cientifico.

Na perspectiva de análise dos fatores etiológicos da depressão Feitosa (2014) diz em seus estudos que esse transtorno é multideterminado e, por isso, deve ser compreendido em sua complexidade, de maneira multifacetada. Na perspectiva de Feitosa (2014) os sintomas depressivos estão relacionados, enquanto fatores de risco, com a vulnerabilidade genética, aspectos da personalidade, eventos de vida estressantes e, sobre fatores de proteção, com a qualidade do suporte social e presença de habilidades sociais.

\section{Espiritualidade e Saúde Mental}

Dada complexidade multifatorial envolta da depressão, ao investigarmos fatores associados do transtorno com qualquer liderança religiosa que seja, devemos tomar o devido cuidado e rigor cientifico. A pergunta que surge é: se a depressão é um transtorno multideterminado e multidimensional devemos levar em conta também a esfera da espiritualidade na vida desses líderes religiosos? A resposta é: sim. Mas não devemos nos ater apenas a esse ponto específico, temos que analisar de maneira global o sofrimento mental que 
acomete tais indivíduos que são tidos por muitos como modelo de conduta espiritual e comportamental. Entretanto, sendo a esfera espiritual um fator tão presente na vida dos pastores, devemos saber sua relação com a saúde mental.

A espiritualidade se encontra numa dimensão mais pessoal e existencial, tais como a crença em (ou uma relação com) Deus ou um poder superior. Muitas pessoas que rejeitam uma religião organizada ou formas tradicionais de culto, dando maior ênfase à experiência espiritual direta, preferem ser definidas como "espirituais" e não como "religiosas". (Dalgalarrondo, 2008)

Segundo Peres et al. (2007), um aspecto importante da relação entre saúde, bem-estar e religião é o papel potencial da religião como forma de lidar com o sofrimento do individuo. Com relação aos aspectos negativos da religião sobre a saúde mental Dalgalarrondo (2008 p.190) diz:

\begin{abstract}
Apesar de a maioria das evidências empíricas apontarem para uma associação positiva entre saúde mental, religião e religiosidade, também há, embora em menor número, evidências empíricas de que, para alguns subgrupos, em determinadas situações e condições de vida, e em certos contextos religiosos, o maior envolvimento religioso pode, ao contrário, estar associado a aspectos negativos da saúde física e mental.
\end{abstract}

Se falarmos sobre saúde física e mental, consequentemente falamos de qualidade de vida, que na visão de Pozatti (2004) é uma demanda a ser estudada tanto em âmbito pessoal, como nas organizações. Pozzati (2004) diz que esta demanda foi constituída através da fragmentação do ser humano sendo sentida em diversos âmbitos do indivíduo, como físico, mental, social, cultural, ambiental e espiritual. Para que o significado de vida, seja efetivo de fato, é necessário olhar o ser humano com um olhar holístico, abrangente, transcendendo assim, a visão mecanicista e materialista.

Para Oliveira (2010) a dimensão da espiritualidade é, pois, a dimensão do sentido, que é a dimensão da afirmação. Porque é nessa esfera que o indivíduo torna-se consciente e compromissado com a busca de sua identidade mais íntima, sua trajetória. Através da espiritualidade o ser humano pode dar sentido à sua existência e à realidade que o cerca.

Campos e Murakami (2012) abordam as dificuldades que os profissionais da área da saúde têm para lidar com a esfera religiosa do paciente, e afirmam que apesar da religiosidade ser cada vez mais reconhecida pela sua importância na saúde, à maioria dos profissionais da área não tem instrução ou treinamento para lidar com essa questão, criando uma lacuna do 
cuidado desenvolvido pelo profissional pela falta de conhecimento da importância que a religião tem na vida dos pacientes.

\section{Metodologia}

$\mathrm{O}$ estudo possuiu delineamento transversal e abordagem metodológica quantitativa e qualitativa. A pesquisa quantitativa adota estratégia sistemática, objetiva e rigorosa para gerar e refinar o conhecimento (Souza, Driessnack \& Mendes, 2007). Segundo Coutinho (2004, p. 441), "o avaliador quantitativo necessita de instrumentos estruturados (como questionários ou entrevistas estruturadas) com categorias estandardizadas que permitam encaixar as respostas individuais".

Na visão de Coutinho (2004, p.439), um dos critérios para definir a forma como se orienta a pesquisa qualitativa é que: "a realidade a avaliar é "objectiva" na medida em que existe independente do sujeito; os acontecimentos ocorrem de forma organizada sendo possível descobrir as leis que os regem para os prever e controlar". Para Sampieri, Collado e Lucio (2013), a coleta de dados quantitativa ocorre pela formulação primária do problema, e por meio disso, elaborar o processo de coleta de dados. Desse modo, são criados instrumentos e métodos que se possam obter e codificar dados passíveis de mensuração e interpretação onde serão arquivados e preparados para análise por meio de computadores. Coutinho (2004) afirma que o avaliador qualitativo busca as opiniões individuais, através de entrevistas não estruturadas ou livres, sem se preocupar em categorizar respostas previamente, dessa forma o método qualitativo visa uma interpretação dos dados.

De acordo com Coutinho (2004, p.439) o estudo quantitativo: "adopta, do ponto de vista ontológico, uma posição relativista - há múltiplas realidades que existem sob a forma de construções mental e socialmente localizadas -, inspira-se numa epistemologia subjectivista que valoriza o papel do investigador/construtor do conhecimento".

Quanto aos procedimentos éticos visando à preservação da bioética, o estudo possui um Termo de Compromisso para Utilização de Dados que garante o anonimato dos membros. Os dados e informações obtidas foram utilizados única e exclusivamente para fins deste estudo. A pesquisa foi aprovada pelo comitê de ética da Universidade do Extremo Sul Catarinense (UNESC), com o Parecer no: 2.083.978 e CAAE: 68328617.0.0000.0119. 
Nesse estudo foram aplicados nos participantes o Inventário Beck de Depressão (BDI) e um questionário com questões fechadas e abertas de conteúdo relacionados à área psiquiátrica em pessoas que exercem alguma função de liderança dentro da Igreja pesquisada. Procurou-se na aplicação do questionário deixar os participantes livres para que pudessem expressar sua opinião (caso quisessem) sobre a problemática em questão, seja em relação a sua vivência pessoal ou de outra pessoa.

Os critérios de inclusão:

- Membros que exercem algum papel de liderança dentro da Igreja Pentecostal;

- Membros que estão a pelo menos 2 anos na instituição;

- Membros que desempenham alguma função eclesiástica dentro da Igreja;

- Líderes reconhecidos pelo Pastor Presidente da Igreja Pentecostal.

Os critérios de exclusão:

- Lideranças não reconhecidas pelo Pastor Presidente da Igreja;

- Lideranças religiosas fora da Igreja Pentecostal pesquisada;

- Membros da instituição que não desempenham qualquer papel de liderança;

- Membros que estejam a menos de 2 anos na instituição.

A análise de dados foi feita posteriormente após leitura, compreensão e tabulação final dos resultados conforme crivo previsto no manual do teste. A apresentação e interpretação de dados se efetuaram por meio dos procedimentos fundamentados na visão de Sampieri, Collado e Lucio (2013), onde a análise de dados quantitativos é realizada de forma informatizada, com computadores, que por meio dos dados inseridos são geradas tabelas e gráficos estatísticos, o que possibilita uma compreensão melhor dados colhidos e, por meio dos resultados, gerar uma interpretação dos dados que não fique presa apenas a procedimentos de cálculo.

\section{Resultados e discussão}

Os resultados da pesquisa foram divididos em duas etapas visando apresentar uma análise individual mais clara dos dados obtidos através do BDI (2011) e do questionário utilizado. Entre os lideres da igreja que participaram 8 eram pastores, e 2 eram evangelistas. A amostra poderia ser maior, isso é inegável. Entretanto, alguns lideres preferiram não participar 
e serem avaliados na pesquisa por questões pessoais. Logo, os participantes presentes foram os que se sentiram confortáveis para falar sobre o assunto. Todos os participantes eram casados e tinham uma média de idade de 46 anos. Em relação a escolaridade pode-se encontrar uma grande variedade como pode-se ver na tabela a seguir:

Tabela 1 - Caracterização dos participantes

\begin{tabular}{lcc}
\hline \multicolumn{1}{c}{ Escolaridade } & Número & Porcentagem \% \\
\hline Ensino Superior Completo & 4 & $40 \%$ \\
Ensino Superior Incompleto & 1 & $10 \%$ \\
Ensino Médio Completo & 2 & $20 \%$ \\
Ensino Fundamental Completo & 3 & $30 \%$ \\
\hline
\end{tabular}

Fonte: Pesquisa dos autores.

Alguns demonstraram interesse sobre o assunto, e tinham certa preocupação em relação ao transtorno, evidenciando um receio em possivelmente estar ou não depressivo. Antes da aplicação do Inventário Beck de Depressão e do Questionário, os participantes costumavam falar sobre sua opinião acerca do tema. Um discurso que se repetiu diversas vezes foi o fato de que as pressões e exigências do cargo recaiam sobre os membros da própria família do líder, ou seja, não havia apenas uma expectativa de como o pastor ou o evangelista deveriam ser ou agir, mas também de sua família.

O BDI (2011), a partir do escore obtido pela escala sintomática dos escores apresenta quatro níveis: mínimo, leve, moderado e grave. A partir da amostra investigada apenas 1 individuo apresentou grau leve de sintomas depressivos, conforme destacado na Tabela 2. Segundo Deus (2009) "Em depressões leves, a pessoa consegue trabalhar e até mesmo dar conta de suas responsabilidades, à custa de cansaço constante, mau humor e irritabilidade em graus variáveis.".

Tabela 2 - Resultado do Inventario Beck de Depressão

\begin{tabular}{c|c|c}
\hline $\begin{array}{c}\text { Não apresentou qualquer } \\
\text { grau de sintomas depressivos }\end{array}$ & $\begin{array}{c}\text { Apresentou grau leve de } \\
\text { sintomas depressivos }\end{array}$ & Amostra Total \\
\hline 9 & 1 & 10 \\
\hline
\end{tabular}

Fonte: Pesquisa dos autores. 
Os indivíduos participantes da pesquisa em sua grande maioria tiveram duvidas em relação às perguntas contidas no questionário, perguntando se deviam responder na perspectiva "terrena" ou no âmbito "espiritual". Para eles, a realidade "terrena" cada vez mais iria piorar, era o que se esperava do mundo, entretanto isso tudo teria um fim, que seria ou a morte ou a vinda de Cristo. Logo, tudo que gerasse angustia tristeza ou qualquer tipo de "mal" cessaria nessa esperança futura. Para eles, existe a certeza de um futuro com eterna paz e felicidade. A aplicação da escala demonstrou essa dificuldade em especifico, pois não há como avaliar o fator espiritual subjetivo numa ótica quantitativa e com perguntas fechadas.

A complexidade pôde ser vista a partir do momento em que os indivíduos relataram estar tristes e sem esperanças com o mundo terreno, mas se alegram no que há por vir, seja pela vida após a morte ou a vinda de Cristo. Para Dalgalarrondo (2008), as noções de fé e crença também são elementos importantes deste campo semântico e fenomênico. A crença pode ser definida como a adesão do individual ao que parece ser ou pode ser verdadeiro. A fé refere-se aos mistérios sobrenaturais, a explicação de fatos que excedem a capacidade do entendimento humana e estão fora das possibilidades de verificação empírica.

Gomes (2011) ao comentar a obra de Jung, constatou que ele considerava a religião um fenômeno extraordinário, complexo e multifacetado que pode ser estudado por diversas disciplinas, incluindo a psicologia. Entretanto, nenhuma das ciências é capaz de compreender e explicar o fenômeno religioso de maneira satisfatória. Entretanto, a religião encanta a realidade humana e a natureza religiosa do homem é um fator social inegável que revela aspectos essências da humanidade.

Podemos ver por meio de Gomes (2011, p.100) a inter-relação entre doença mental e religião:

\footnotetext{
A saúde e a doença não são imunes às crenças, sejam elas científicas ou religiosas. É frequente que psiquiatras, psicólogos e outros profissionais de saúde mental ignorem ou critiquem crenças religiosas de seus pacientes. É também frequente que líderes religiosos tenham reservas em relação aos tratamentos em saúde mental. Entretanto, pacientes psiquiátricos dão grande importância às suas crenças e atribuem a elas um papel primordial no lidar com sua doença. Vários autores têm identificado problemas para pacientes que têm um modelo de doença muito diferente de seus médicos, resultando em pior adesão ao tratamento.
} 
Temos que ter em mente que a relação entre saúde mental, espiritualidade e religião é um terreno abstrato, que deve ser analisado levando em consideração a construção histórica, cultural e social, não deixando de negar os aspectos subjetivos e transcendentes da compreensão do próprio individuo e comunidade sobre o tema. Gomes (2011) exemplifica a obra de Jay Adams como algo que influencia as esferas citadas acima, a critica do autor é que a obra de Adams vai à contramão da visão holística sobre o tratamento da depressão, visto que acabou influenciando a compreensão da doença mental em vários segmentos do cristianismo. Pois, sua compreensão sobre doença mental tem como base o pressuposto de que a culpa está diretamente relacionada à violação de qualquer principio sagrado, logo o pecado e a culpa são as causas principais para o surgimento da doença mental. A visão de Adams acaba sendo uma visão primitiva, pré-psicológica e pré-psiquiátrica sobre a doença mental.

Resultado do Questionário

O questionário aplicado revelou dados importantes que não apareceriam na aplicação do BDI (2011). Tais dados encontram-se na Tabela 3:

Tabela 3 - Questionário

\begin{tabular}{|c|c|}
\hline \multicolumn{2}{|c|}{ Você toma algum tipo de medicação psiquiátrica? } \\
\hline Sim & 4 \\
\hline Não & 6 \\
\hline \multicolumn{2}{|c|}{$\begin{array}{l}\text { Tipo de medicação psiquiátrica encontradas na } \\
\text { amostra. }\end{array}$} \\
\hline Bromazepam & 1 \\
\hline Lítio & 1 \\
\hline Escitalopram & 1 \\
\hline Quetiapina & 1 \\
\hline Rivotril & 2 \\
\hline \multicolumn{2}{|l|}{ Tempo de uso da medicação. } \\
\hline $1 \mathrm{a} 11$ meses & 1 \\
\hline $1 \mathrm{a} 2$ anos & 3 \\
\hline \multicolumn{2}{|l|}{ Já procurou ajuda psiquiátrica? } \\
\hline Sim & 5 \\
\hline Não & 5 \\
\hline \multicolumn{2}{|l|}{ Se sim, por qual motivo? } \\
\hline Ansiedade & 2 \\
\hline Dificuldade dormir & 2 \\
\hline Irritação & 2 \\
\hline Estresse por causa da profissão & 2 \\
\hline Luto & 1 \\
\hline
\end{tabular}




\begin{tabular}{c|c}
\hline \multicolumn{2}{c}{ Já teve ou tem algum diagnostico psiquiátrico? } \\
\hline $\begin{array}{c}\text { Transtorno de Ansiedade } \\
\text { Generalizada }\end{array}$ & 1 \\
\hline Transtorno Bipolar & 1 \\
\hline Já fez psicoterapia? & 2 \\
\hline Sim & 8 \\
\hline Não
\end{tabular}

Fonte: Pesquisa dos autores.

Um número considerável da amostra já buscou ajuda de algum psiquiatra (50\%) enquanto 40\% fazem uso de alguma medicação psiquiátrica. Segundo Deus (2009), devido à complexidade do assunto, os pastores assim como outros líderes, precisam se mostrar sempre fortes, pois são modelos, e apresentam grande dificuldade em aceitarem-se doentes, o que corrobora com a discrepância dos resultados dos testes e as respostas dos questionários. Outro fator que pode estar relacionado a essa discrepância é a dificuldade em avaliar os sintomas por meio da dicotomização que os mesmos fazem entre a vida "terrena" e "espiritual".

Um dado relevante que deve ser analisado são os motivos pelos quais os lideres da igreja procuraram ajuda psiquiátrica. Sintomas como ansiedade, irritação, dificuldade para dormir podem ser fatores que podem estar associados à depressão. Outro sintoma relatado foi o estresse por causa da profissão e de acordo com Feitosa (2014) existe a possibilidade de fontes estressoras gerarem sintomas depressivos.

Existe um conjunto de variáveis que podem estar relacionadas à depressão nos lideres religiosos, especificamente, os pastores, Deus (2008, p.121) exemplifica da seguinte maneira:

\begin{abstract}
De contacto no atendimento médico aos mesmos, sabe-se que, devido a condições peculiares e particulares do exercício do pastorado, os pastores, a exemplo dos líderes de outros segmentos da sociedade, apresentam inúmeras variáveis que tornam especialmente difícil para eles lidar com estados de fragilização, como o fato de estar doente. O pastor, o líder carismático, ungido, investido da imagem do "homem de Deus" na comunidade aliado à atitude de estar sempre pronto e disponível para as atividades pastorais, as quais frequentemente demandam por uma alternância de emoções, como observado nas seguintes atividades: sepultamento pela manhã, reunião de liderança à tarde, casamento em final de tarde e culto à noite, ou seja, a vivência, num mesmo dia, da dor e do luto, o exercício da lógica e preocupação, celebração de momento de alegria, prédica e exortação e todas as emoções sentidas, expressas e contidas pelo veículo sagrado.
\end{abstract}

A questão é que pastores/lideres religiosos acabam sendo os modelos de conduta espiritual e comportamental para os membros da comunidade religiosa onde estão inseridos. 
Talvez a tristeza, o abatimento, ou a angustia possa passar a impressão para os demais de um "mal testemunho", sendo o sofrer desse líder algo que demonstre um sinal de fraqueza e incapacidade de liderar, gerando consequentemente um desencorajamento dos membros.

O pastor deve estar em prontidão para atender as demandas da igreja, deve manter-se firme e passar por situações que muitas vezes podem ser conflituosas com os membros da comunidade. Além de exercer um papel de mediador de relações e conflitos, exerce também um papel de administrador. Sendo a igreja uma instituição filantrópica, o pastor depende muitas vezes das doações espontâneas da comunidade, seja para fazer a manutenção da igreja, ou sustentar a si e sua família. Depender das doações pode ser um fator que contribua para a instabilidade financeira dos pastores, sendo um fator de preocupação constante.

Podemos encontrar respaldo em Deus (2008), pois um aspecto relevante na amostra de sua pesquisa revelou que a causa da depressão nos pastores está ligado ao stress de sua profissão, sendo relacionado com problemas em sua igreja local; falta de apoio e compreensão da Igreja; problemas financeiros advindos da baixa remuneração profissional e etc.

De acordo com Ebert e Soboll (2009), o Pastor ao responder às exigências e demandas que surgem, acaba tendo um ritmo de trabalho intenso e constante, levando em conta as imprevisibilidades que surgem, os limites de tempo e descanso. Ebert e Soboll (2009, p.210) se referem à profissão do Pastor como:

[...] um soldado em guerra, os pastores vivenciam individualmente, a luta pela sobrevivência dentro das organizações religiosas, cada vez mais exigentes e focadas em resultados, de forma semelhante ao que se assiste nas organizações produtivas. A autonomia e a flexibilidade aparentes na definição das tarefas e dos horários são contrapostas com as cobranças simbólicas (da religião) e concretas (da comunidade e da estrutura hierárquica religiosa). Sendo assim, a irrepreensibilidade e o sucesso são os padrões referenciais para a realização do trabalho pastoral. A vivência de sofrimento se apresenta nesse contexto, especialmente pela falta de reconhecimento, pelo distanciamento dos pares. A mobilização de estratégias defensivas de distanciamento não favorece a transformação desta realidade.

De acordo com Volpato et al. (2005), no tocante às medicações, o Bromazepam é indicado em casos de Transtorno de Ansiedade Generalizada, cujo transtorno consta na amostra. Com relação ao Transtorno Bipolar, encontramos na amostra o uso de medicações que estão relacionadas ao tratamento do transtorno como o Lítio, Ecitalopram e Quetiapina. O Rivotril pode ser utilizado como medicação para aliviar sintomas relacionados à inquietude, agitação ou insônia. 
Identifica-se na amostra a forte adesão a procura do psiquiatra $(50 \%)$ em relação à psicoterapia (20\%), essa diferença talvez se dê pelo fato dos pastores/evangelistas se verem como alguém que aconselha, media e ajuda os membros da comunidade que possuem algum problema, mas quando a situação se inverte existe uma resistência na aceitação do seu próprio problema. Dessa forma, a medicação psiquiátrica acaba sendo uma forma de aliviar os sintomas e acobertar as dificuldades que se está passando.

\section{Considerações Finais}

O estudo revelou que, embora apenas $10 \%$ da amostra tenham apresentado grau leve de depressão, outros fatores devem ser analisados em pesquisas posteriores. A amostra identificou outros transtornos psiquiátricos que devem ser investigados nas lideranças religiosas evangélicas. Uma das causas encontradas para o sofrimento psicológico na pesquisa é o estresse por causa da profissão, esse fator coincide com o estudo de Deus (2009) acerca da depressão em pastores. Deus (2009, p.201) afirma que: "Seria possível traçar comparação entre os pastores protestantes e os executivos de alta performance, sem, entretanto, terem o suporte e as benesses das corporações nas quais os executivos atuam; até porque Igreja não é corporação.” Essa visão corrobora com a análise psicodinâmica do trabalho pastoral proposta por Eberte e Soboll (2009), classificando o exercício da profissão como um "soldado em guerra" que luta para sobreviver dentro da organização religiosa, cujo ritmo de trabalho é intenso e constante, limitando até mesmo seu tempo de descanso.

A hipótese a ser considerada nesse estudo é que o estresse causado pelo exercício da profissão pastoral ou de líder de uma comunidade cristã possa ser um fator desencadeante de transtornos não apenas de humor, mas também de ansiedade. Devido ao número da amostra ser pequeno é necessário que se avalie os referidos fatores num estudo mais amplo e que leve em consideração as variáveis encontradas na pesquisa. Entretanto, por causa da resistência encontrada entre os líderes para participar da pesquisa será necessário avaliar pastores e líderes de diversas denominações cristãs. Essa resistência pode ser vista no relato de alguns líderes que não quiseram participar da pesquisa, afirmando que não se sentiriam bem ao serem "avaliados" e que não gostariam de falar sobre o assunto. 
Os resultados desse estudo contribuem para o campo da saúde mental, ampliando as possibilidades de investigação e pesquisa nessa área, visto que a literatura não aborda de maneira frequente esse tema, sendo essa uma das dificuldades encontradas na construção deste artigo. A relevância dos dados encontrados se dá por meio da contribuição cientifica em uma área pouco explorada, o sofrimento psíquico de líderes religiosos.

\section{Referências}

AMERICAN PSYCHIATRIC ASSOCIATION. Manual diagnóstico e estatístico de transtornos mentais. 5. ed. Porto Alegre: Artmed, 2014. 992p.

COUTINHO, C. P. Quantitativo versus qualitativo: questões paradigmáticas na pesquisa em avaliação. Colóquio da Admee-Europa, Lisboa, Portugal, p. 437-448, 2004.

CUNHA, J. A. Manual da versão em português das Escalas Beck. São Paulo: Casa do Psicólogo, 2011. 171p.

DALGALARRONDO, P. Religião, psicopatologia \& saúde mental. Porto Alegre: Artmed, 2008. 288p.

DEUS, P. R. G. A influência do sentimento religioso sobre cristãos portadores de depressão. Dissertação (Mestrado em Ciências da Religião) - Universidade Presbiteriana Mackenzie, São Paulo, 2008. 147p. Disponível em: <http://tede.mackenzie.br/jspui/bitstream/tede/2499/1/Persio\%20Ribeiro\%20Gomes\%20de\% 20Deus.pdf $>$. Acesso em: 14 nov. 2017.

DEUS, P. R. G. Um estudo da depressão em pastores protestantes. Ciências da Religião História e Sociedade, v. 7, n. 1, p. 189-202, p. 2009. Disponível em: <http://editorarevistas.mackenzie.br/index.php/cr/article/viewFile/1134/849>. Acesso em: 10 fev. 2018.

EBERT, C.; SOBOLL, L.; PEREIRA, A. O trabalho pastoral numa análise da Psicodinâmica do Trabalho. Aletheia, Canoas, n. 30, p. 197-212, 2009. Disponível em: <http://www.ulbra.br/upload/7421b725e454e115707eeccaf477a416.pdf >. Acesso em: 25 abr. 2018.

FEITOSA, F. B. A depressão pela perspectiva biopsicossocial e a função protetora das habilidades sociais. Psicol. cienc. prof., Brasília , 2014, v. 34, n. 2, pp. 488-499. Recuperado em: http://www.scielo.br/pdf/pcp/v34n2/v34n2a16.pdf 
GOMES, A. M. A. Um olhar sobre depressão e religião numa perspectiva compreensiva. Estudos de Religião, v. 25, n. 40, 2011, pp.81-109, jan./jun. Recuperado de: https://www.metodista.br/revistas/revistas-ims/index.php/ER/article/view/2368/2555

MURAKAMI, R. e CAMPOS, C. J, G. Religião e saúde mental: desafio de integrar a religiosidade ao cuidado com o paciente. Rev. bras. enferm., Brasília , v. 65, n. 2, p. 361367, Apr. 2012. Recuperado de: http://www.scielo.br/pdf/reben/v65n2/v65n2a24.pdf

OLIVEIRA, J. F. P. A Espiritualidade e o Corpo. In: Santos, Franklin Santana (org.). Arte de cuidar: Saúde, Espiritualidade e Educação. Bragança Paulista: Comenius, 2010. p. 91-107.

POZATTI, M. L. (2004). Educação, qualidade de vida e espiritualidade. In: Teixeira, E. F. B.; Muller, M. C. \& Silva, J. D. T. (Org.). Espiritualidade e Qualidade de Vida. Porto Alegre: EDIPUCRS, pp.193-205.

Secretaria de Estado da Saúde (SES-SC). Protocolos da Rede de Atenção Psicossocial de Santa Catarina - Florianópolis, 2016, p.470. Recuperado de: http://portalses.saude.sc.gov.br/phocadownload/Regulacao/protocolos/Protocolos\%20da\%20 RAPS\%20-\%20Livro\%20para\%20download.pdfL

SAMPIERI, R. H.; Collado, C. F. \& Lucio, M. P. B. Metodologia de Pesquisa. 5.ed Porto Alegre: Penso, 2013, 623 p.

SEZINI, A. M. \& GIL, C. S. G. C. Nutrientes e depressão. Vita et Sanitas., Trindade-Go, n.08, 2014, jan-dez. Recuperado de: http://www.fug.edu.br/revista/index.php/VitaetSanitas/article/view/29/21

SOUSA, V. D; DRIESSNACK, M.; MENDES, I. A. C. Revisão dos desenhos de pesquisa relevantes para enfermagem: Parte 1: desenhos de pesquisa quantitativa. Rev. Latino-Am. Enfermagem, Ribeirão Preto, v. 15, n. 3, p. 502-507, June, 2007. Recuperado de: http://www.scielo.br/pdf/rlae/v15n3/pt_v15n3a22.pdf

TAVARES, L. A. T. A depressão como "mal-estar" contemporâneo: medicalização e (ex)sistência do sujeito depressivo. São Paulo: Editora UNESP; São Paulo: Cultura Acadêmica, 2010, 371 p. Recuperado de: https://static.scielo.org/scielobooks/j42t3/pdf/tavares9788579831003.pdf

VOLPATO, A. C.; GALLOIS, C. B. e ISOLAN, L. Psicofármacos: consulta rápida. 3.ed. Porto Alegre: Artmed, 2005, p.695.

MURAKAMI, R. e GOMES CAMPOS, C. J. Religião e saúde mental: desafio de integrar a religiosidade ao cuidado com o paciente. Revista Brasileira de Enfermagem, 65(2). 2012.

PERES, M. F. P., ARANTES, A. C. D. L. Q., LESSA, P. S., \& CAOUS, C. A. A importância da integração da espiritualidade e da religiosidade no manejo da dor e dos cuidados paliativos. Archives of Clinical Psychiatry, 2007. 
WORLD HEALTH ORGANIZATION. Depression; 2018 [acesso em 12 junho 2018]. Recuperado de: http://www.who.int/en/news-room/fact-sheets/detail/depression

\section{Como citar este artigo (Formato ABNT):}

NUNES, Rafael Zaneripe de Souza; SOUZA, Rosimeri Vieira da Cruz de;CASTRO, Amanda. Fatores Associados à Depressão em Líderes Religiosos de uma Denominação Pentecostal. Id on Line Rev.Mult. Psic., 2018, vol.12, n.42, p. 367-382. ISSN: 1981-1179.

Recebido: 16/09/2018;

Aceito: 19/09/2018 